\title{
A Hybrid Flower Pollination Algorithm with Sequential Quadratic Programming Technique for Solving Dynamic Combined Economic Emission Dispatch Problem
}

\author{
Rabia Noreen Gul ${ }^{1 \mathrm{a}}$, Aftab Ahmad ${ }^{1 \mathrm{~b}}$, Saqib Fayyaz ${ }^{1 \mathrm{c}}$, Muhammad Kashif Sattar ${ }^{1 d}$, \\ Syed Saddam ul Haq ${ }^{1 e}$
}

RECEIVED ON 11.03.2019, ACCEPTED ON 03.03.2020

\begin{abstract}
This paper presents the solution of highly complex, non-linear, multi-objective Dynamic Combined Economic Emission Dispatch (DCEED) problem. DCEED is a power system optimization problem with conflicting objectives of fuel cost and emission. DCEED includes constraints like valve point loading effect, Transmission Losses and Ramp Rate limits. Solution of DCEED problem is given by a novel Hybridized Flower Pollination Algorithm (FPA) with Sequential Quadratic Programming (SQP). FPA is a nature inspired population based meta-heuristic optimization technique that models its search on the flower pollination process. The non-convex nature of generation because of numerous operational, physical and dynamic constraints, makes search space highly multi model and complex. This makes DCEED a challenging as well as an attractive problem for research. The effectiveness of FPA-SQP is tested and validated by applying it on IEEE Standard 5-unit and 10unit non-convex test system in MATLAB environment for the time interval of 24 hours. The results achieved by this algorithm show significant reduction in cost and emission as compared to other available techniques in the literature.
\end{abstract}

Keywords: Flower Pollination Algorithm, Sequential Quadratic Programming, Emission Dispatch, Dynamic Combined Economic Emission Dispatch.

\section{INTRODUCTION}

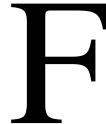
or a developing country like Pakistan, Turkey, China etc. The importance of economics cannot be over emphasized. Pakistan's power industry is currently in a very serious downfall with severe power shortage and no hope to recover from this deficit soon. No matter how dire the situation maybe it still presents opportunity for smart minds in power system operation to devise strategies to schedule power system of country such that it requires minimum cost for operation. Allocating optimum power to a generating unit with the objective to minimize fuel cost while observing constraints is termed as Economic Dispatch (ED) [1, 2] problem. If this allocation of power is limited to a single fixed demand it is termed as static ED and if this power scheduling is done on a 24 hour time window it is termed as dynamic ED [3]. Many researchers have worked on ED and its variants achieving minimized costs, saving millions of dollars per year. But only minimization of fuel cost is not enough to achieve a sustainable and long-term solution for a heavily fossil fuel reliant power industry like Pakistan. Pakistan has been listed among top 10 countries most affected by climate change. The lack of choice in resources and the associated time in developing new clean sources makes it inevitable to use fossil fuel-based energy

${ }^{1}$ Department of Electrical Engineering, University of Engineering and Technology Taxila, Taxila, Pakistan. Email: ${ }^{a}$ rabiagul.1992@yahoo.com, baftab.ahmad@uettaxila.edu.pk (Corresponding Author), csaqib_fayyaz@outlook.com, dmkashifsattar94@gmail.com, essadamulhaq@ gmail.com

This is an open access article published by Mehran University of Engineering and Technology, Jamshoro under CC BY 4.0 International License. 
system but along comes all the environmental issues associated with it. Pollutants like $\mathrm{CO}_{2}, \mathrm{SO}_{2}$ and $\mathrm{NO}_{\mathrm{x}}$ are discharged into the environment due to burning of fossil fuels like furnace oil [4]. These pollutants affect humans as well as many other life-forms which include animals, fish, birds and plants. They are also reported to causes damage to the materials, reducing visibility and cause global warming. Therefore a strategy is needed to protect the environment while overcoming the electricity crisis and to create sufficient and safe electricity, not only at the lowest cost but also at low level of pollution [5].

Reduction in emission can be achieved by shifting the load of the industry on a more environment friendly emission less energy resources [6] but their development requires the luxury of time which we do not have on our hands. Other alternative to reduce emission is by using equipment that funnels out pollutants from the exhaust of fossil fuel plants not allowing them to get dispersed in environment [7]. These options although less time intensive, requires investment that is not beneficial to energy producer but may even appear to them as a penalty. To achieve emission reduction while not straining energy producers, only feasible option is to perform emission dispatch. Emission Dispatch $(\mathrm{EmD})$ is done by scheduling of generator units with the considerations of minimizing emission. EmD has many forms is literature depending on the nature of objective expression used and constraints considered. First form of EmD expresses fuel cost as objective function and considers emission as a constraint [8] but this setting between fuel cost and emission leads to complexity in achieving trade-off between them [9]. Second form of EmD considers fuel cost and emission as a single objective expression with unified constraints $[10,11]$ but this unification inhibits us to focus and target on fuel cost or emission individually. Third form of EmD considers emission and fuel cost as two different objective functions tied together in a single multi objective expression by assigning weights to each objective [12]. This setting allows flexibility in solution as well as individual autonomy and because of these strengths we use this form in our research.

A lot of mathematical techniques have been reported in literature to solve power system optimization problems. ED problem has been the talk of many research ventures since many decades. Initial attempts *made at the solution of ED problem included classical approaches like Lagrange relaxation method [13], linear programming, non-linear programming, integer programming [14], dynamic programming [15], direct search method [16] and Quadratic programming [17]. These initial attempts showed encouraging results, but more realistic non-convex complex problems proved to be too much of a task for these approaches. Classical approaches were dominantly dependent on selection of initial point and tended to get stuck in local optima's therefore as systems became more complex, they were unable to provide remarkable results. Another classical deterministic technique, Dynamic Programming showed better results when solving non-convex problems but it suffered from the curse of dimensionality [18]. To deal with these complexities' researchers created more optimization techniques that were free of the bounds of initial point selection and had complex procedure either nature inspired, based on some specie or a physical law that propelled a solution set from initial feasible point to an optimum point in the allotted search space. These techniques are broadly categorized as evolutionary, nature inspired meta-heuristic or stochastic approaches and some of these famous techniques or their variants include, Differential Evolution (DE) [19], Particle Swarm Optimization (PSO) [20-22], Artificial Immune System (AIS) [23], Hopfield neural network [24], Genetic Algorithm (GA) [25], evolutionary programming [26], Tabu search algorithm [27], selforganizing migrating algorithm [28], and cuckoo search algorithm [29, 30], Modified Artificial Bee Colony Optimization (MABC) [31], Non-Sorting Genetic Algorithm (NSGA) [32], Improved Bacterial Foraging Algorithm (IBFA) [33], Bee Colony Optimization with Sequential Quadratic Programming (BCO-SQP) [34], Differential Evolution with Sequential Quadratic Programming (DE-SQP), Particle Swarm Optimization with Sequential Quadratic Programming (PSO-SQP) [4] etc.

DCEED problem has also been attempted by some of these techniques or their variants. In Elaiw et al. [4] solved non-convex DCEED problem having valve point effect by two hybridized algorithms i.e. DE-SQP 
and PSO-SQP. Two different test systems were simulated, and the results achieved showed great potential for hybridization of optimization techniques with SQP. Taking inspiration from this work we have proposed a hybrid FPA-SQP technique to solve the non-convex DCEED problem having valve point effect.

\section{MATHEMATICAL FORMULATION}

This section presents the mathematical formulation and constraints expressions involved in DCEED problem.

\subsection{Fuel Cost Function}

The cost expression of a thermal unit over $\mathrm{T}$ time horizon can be approximated by a quadratic equation as shown in equation (1).

$\mathrm{C}_{\text {Total }}=\sum_{\mathrm{t}=1}^{\mathrm{T}} \mathrm{C}_{\mathrm{T}}=\sum_{\mathrm{t}=1}^{\mathrm{T}} \sum_{\mathrm{j}=1}^{\mathrm{N}} \mathrm{a}_{\mathrm{j}} \mathrm{P}_{\mathrm{j}}^{2}+\mathrm{b}_{\mathrm{j}} \mathrm{P}_{\mathrm{j}}+\mathrm{c}_{\mathrm{j}}$

where $\mathrm{j}$ is the number of committed generator units, $\mathrm{C}_{\mathrm{t}}$ is cost of generation at $\mathrm{t}$ time interval, $\mathrm{N}$ is total number of generating units, $P_{j}$ is scheduled power for $\mathrm{j}^{\text {th }}$ unit and $\mathrm{a}, \mathrm{b}, \mathrm{c}$ are fuel cost coefficients.

Equation (1) is a reasonable approximation in order to obtain initial solution but when practical constraints like valve point effect of thermal units are considered then equation (1) cannot completely explain the nonconvexity and multi-modal behavior by simple quadratic cost expression. The valve point effect creates non-linearity in the smooth cost curve of thermal generators making it bumpy and multi modal. This non-convex behavior can be expressed by augmenting the equation (1) with a sinusoidal expression as shown in Equation (2).

$$
\begin{aligned}
& \mathrm{C}_{\text {Total }}=\sum_{\mathrm{t}=1}^{\mathrm{T}} \sum_{\mathrm{j}=1}^{\mathrm{N}} \mathrm{a}_{\mathrm{j}} \mathrm{P}_{\mathrm{j}}^{2}+\mathrm{b}_{\mathrm{j}} \mathrm{P}_{\mathrm{j}}+\mathrm{c}_{\mathrm{j}}+ \\
& \left|\mathrm{e}_{\mathrm{j}} \sin \left(\mathrm{f}_{\mathrm{j}}\left(\mathrm{P}_{\mathrm{j}, \text { min }}-\mathrm{P}_{\mathrm{j}}\right)\right)\right|
\end{aligned}
$$

where $\mathrm{e}, \mathrm{f}$ are additional fuel co-efficient due to rippling effect and $\mathrm{P}_{\mathrm{j}, \mathrm{min}}$ is the lower bound of $\mathrm{j}^{\text {th }}$ unit.

\subsection{Emission Function}

$\mathrm{CO}_{2}, \mathrm{SO}_{2}$ and $\mathrm{NO}_{\mathrm{x}}$ are the major emissions of a conventional fossil fuel fired power plant. The emission of $\mathrm{CO}_{2}, \mathrm{SO}_{2}$ is expressed by using quadratic equation where as $\mathrm{NO}_{\mathrm{x}}$ is expressed by using exponential equation. The total emission over a time period $\mathrm{T}$ can be modeled as shown in Equation (3).

$$
\begin{aligned}
\mathrm{E}_{\text {Total }}=\sum_{\mathrm{t}=1}^{\mathrm{T}} \mathrm{E}_{\mathrm{t}}= & \sum_{\mathrm{t}=1}^{\mathrm{T}} \sum_{\mathrm{j}=1}^{\mathrm{N}} \alpha_{\mathrm{j}}+\beta_{\mathrm{j}} \mathrm{P}_{\mathrm{j}}+\gamma_{\mathrm{j}} \mathrm{P}_{\mathrm{j}}^{2} \\
& +\eta_{\mathrm{j}} \mathrm{e}^{\lambda_{\mathrm{j}} \mathrm{P}_{\mathrm{j}}}
\end{aligned}
$$

where $E_{t}$ is the emission at time interval, $\alpha, \beta, \gamma, \eta$ and $\lambda$ are pollutant coefficients, $\mathrm{N}$ is total number of generating units and $P_{j}$ is scheduled power for $j^{\text {th }}$ unit.

\subsection{Objective Function}

DCEED is multi-objective power system optimization problem with the final goal to achieve minimized fuel cost and emission at a particular-level of demand on a specified time horizon such that no operational or physical constraint is violated. The minimization of total fuel cost and emission are self-competing objectives which causes increase in the result of one as other is minimized. To overcome this obstacle and create a unified minimization expression we assign weights to each objective by defining a weighting factor " $w$ " resulting in an expression shown in Equation (4).

$$
\min \mathrm{Obj}=\min \{w C+(1-w) E\}
$$

where $\mathrm{C}$ is non-convex, cost function and $\mathrm{E}$ is nonlinear emission function, $w$ is a weighting factor whose value may be selected by system operator in therange 0-1 depending upon regulatory requirements or user preferences. Changing the value of $w$ will lead to different solutions. Selecting $w=0$, will minimize

(2) emissions only, while increasing $w$, will increase emissions and will reduce cost, and setting $w=1$ will optimize cost only. Summation of weight factors of each objective function will be equal to one. Addition of constraints to multi-objective DCEED problem makes non-convex, non-linear and computationally intensive. 


\subsection{Constraints}

Unit Bounds Constraints: Scheduling of committed machines must be within their upper and lower bounds

$$
\mathrm{P}_{\mathrm{j}, \text { min }} \leq \mathrm{P}_{\mathrm{j}} \leq \mathrm{P}_{\mathrm{j}, \mathrm{max}} \text { forj }=1,2,3, \ldots, \mathrm{N}
$$

where $P_{j}$ is the active power output of $j^{\text {th }}$ machine and $\mathrm{P}_{\mathrm{j}, \mathrm{min}}$ and $\mathrm{P}_{\mathrm{j}, \mathrm{max}}$ are its upper and lower limits.

Power Balance Constraint: Output Power of all the machines must be equal to demand plus transmission losses.

$$
\sum_{j=1}^{N} P_{j}-P_{D}-P_{L}=0
$$

where $\mathrm{P}_{\mathrm{D}}$ is demand, $P_{L}$ represent transmission losses incurred at the specified level of generation.

Transmission losses can be determined through load flow or by application of quadratic Kron's formula.

$$
P_{L}=\sum_{i=1}^{N} \sum_{j=1}^{N} B_{i j} P_{i} P_{j}+\sum_{i=1}^{N} B_{o i} P_{i}+B_{00}
$$

Ramp Rate Constraint: Ramp rate is defined as power response capability of on-line generating units in terms of accommodating power changes in specified time intervals. Operating range of all the generating units is limited by ramp rate.

$$
\left\{\begin{array}{c}
\mathrm{DR}=\mathrm{P}_{\mathrm{j}, \min } \text { fort }=1 \\
\mathrm{UR}=\mathrm{P}_{\mathrm{j}, \mathrm{max}} \text { fott }=1 \\
\mathrm{P}_{\mathrm{it}}-\mathrm{P}_{\mathrm{i}(\mathrm{t}-1)} \leq \text { URfort }>1 \\
\mathrm{P}_{\mathrm{i}(\mathrm{t}-1)}-\mathrm{P}_{\mathrm{it}} \leq \text { DRfort }>1
\end{array}\right.
$$

\section{PROPOSED HYBRID FLOWER POLLINATION ALGORITHM WITH SQP}

\subsection{Flower Pollination Algorithm}

Population based meta-heuristic optimization techniques start their search by selecting a feasible non-optimum point randomly in search space and then propel this point to feasible optimum point through two distinct stages of search namely local and global search. These stages of search are governed by mathematical expressions that mimic either an animal's behavior in nature or a natural phenomenon. One such optimization technique that mimics the flower pollination process in nature is FPA that was proposed by Yang et al. [35]. FPA is a populationbased optimization strategy that is based on principle of evolution. Like all population-based strategies FPA inherent the strengths of initial point independency and local optima avoidance. The two distinct phases of search as depicted by all population-based strategies also exist in FPA and they are termed as local and global pollination. FPA initially generates a random population of flowers which then evolve in each iteration through local and global pollination process until they reach optimum point. The global pollination process mimics biotic or cross pollination in which a pollinator disperses pollen to flower. This behavior can be expressed by Levy flight Equation (9) as:

$$
x_{i}^{t+1}=x_{i}^{t}+L\left(g_{*}-x_{i}^{t}\right)
$$

where $x_{i}^{t}$ is the $\mathrm{i}$-th flower at $\mathrm{t}$-th iteration, $\mathrm{L}$ is the Levy constant and $g_{*}$ is the current optimum.

Local pollination mimics abiotic or self-pollination process which does not require a pollinator and it is expressed as.

$$
x_{i}^{t+1}=x_{i}^{t}+€\left(x_{j}^{t}-x_{k}^{t}\right)
$$

where $x_{i}^{t}, x_{j}^{t}, x_{k}^{t}$ are different flowers at $\mathrm{t}$-th iteration and $€$ is a constant randomly selected from normal distribution in range $(0,1)$.

In order to control how much local or global pollination is performed a constant $\mathrm{p}$ is defined known as switch probability.

$$
\left\{\begin{array}{c}
\text { GlobalPollinationIfrand }<p \\
\text { LocalPollinationelse }
\end{array}\right.
$$

Another parameter includes flower constancy which indicates the reproduction probability for flower specie, and it is proportional to visit of pollinators to particular flower type but here for simplicity we have assumed single species of flowers.

Like all population-based approaches FPA shows remarkable strengths in local optimum avoidance but

Mehran University Research Journal of Engineering and Technology, Vol. 40, No. 2, April 2021 [p-ISSN: 0254-7821, e-ISSN: 2413-7219] 
FPA lacks in locating exact position of global optima. FPA like all population approaches can achieve near optimum convergence and requires additional assistance to enhance its tracking capabilities ensuring precision in locating global optimum. This enhancement is provided here by hybridizing it with SQP technique which is highly dependent of a strong starting point and has extraordinary local exploitation characteristics. In proposed strategy FPA provides its best solution to SQP as starting point, SQP than performs rigorous local space exploitation to locate global optimum. This strategy greatly enhances the shortcomings of FPA making it exceptional in tracking global optima with precision. Algorithm of proposed FPA-SQP is given below and Flow chart of the proposed technique is given in Fig. 1.

\section{Algorithm:}

1. Initialization: First, the population is randomly initialized in between upper and lower limit of all the generators, according to the following equation:

$$
\begin{aligned}
& \operatorname{Sol}(i, j)=P_{\max }(j)-\left(P_{\max }(j)-\right. \\
& \left.P_{\min }(j)\right) \times \operatorname{rand}(0 \sim 1)
\end{aligned}
$$

2. Calculate Fitness: In this step we evaluate fitness of solution by calculating objective functions equation (4) and check for constraints violation.

3. Create New Population by Local/Global Pollination: The pollination type is selected by comparing a random number generated with probability switch pas depicted in equation (11). Depending on value of $\mathrm{p}$ we perform global pollination equation (9) or local pollination equation (10).

4. Update Population: In this step first, we check for constraint violation, then recalculate fitness for each flower and update the respective entries if new value is less than previous fitness value.

5. Sort and Repeat: The flower population is sorted in ascending order according to the fitness value and above steps from 2 to 4 are repeated till maximum iteration.

6. Initializing SQP: The best answer found from FPA is used as starting point to perform SQP.

7. Stopping Criteria: SQP refines answer until predefined number of decimal points or maximum iteration limit is reached.

The SQP sub-problem formulation is taken from $[34,36]$ and a basic SQP problem solution process is shown in Fig. 2.

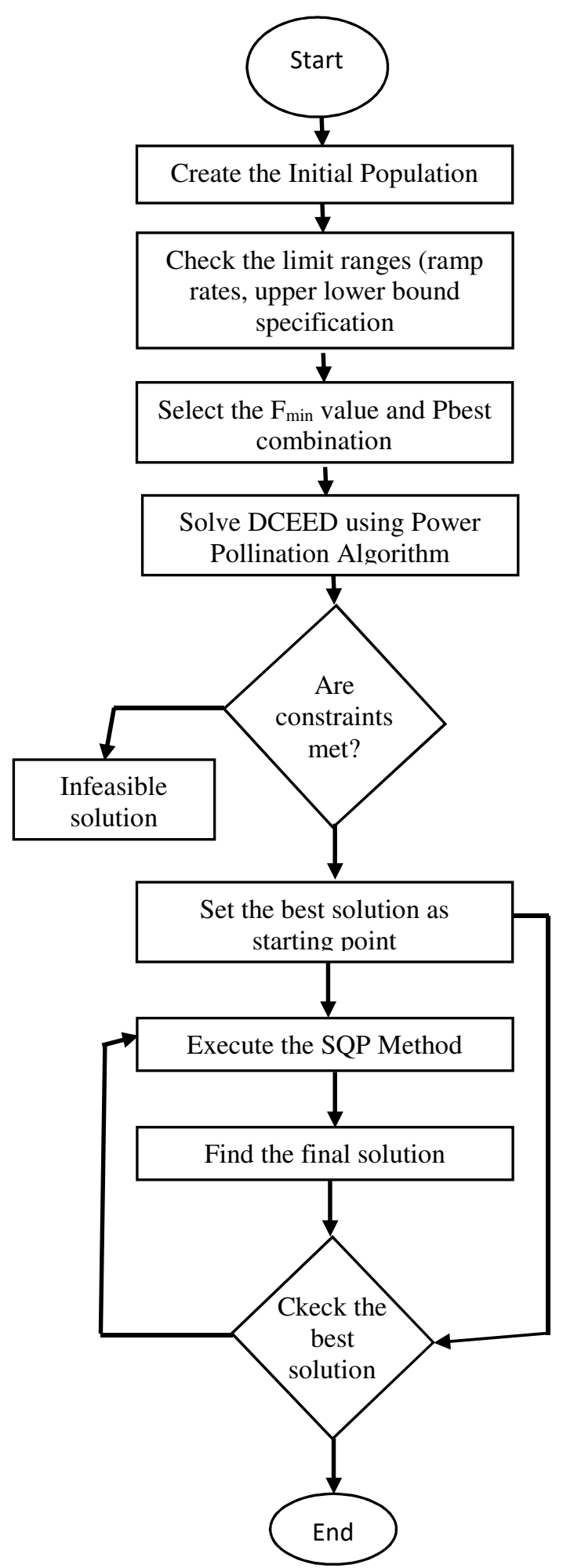

Fig. 1: Proposed Hybrid FPA-SQP Algorithm Flow Chart 


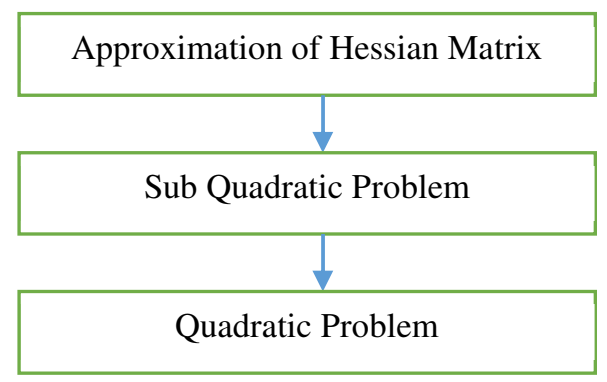

Fig. 2: Sequential Quadratic Programming Steps

The main objective is to model the minimized objective function through the SQP as a sub-problem.

$$
\frac{1}{2} \mathrm{~d}_{\mathrm{k}}^{\mathrm{T}} \mathrm{H}_{\mathrm{k}} \mathrm{d}_{\mathrm{k}}+\nabla \mathrm{f}\left(\mathrm{x}_{\mathrm{k}}\right)^{\mathrm{T}} \mathrm{d}_{\mathrm{k}}
$$

subject to:

$$
\begin{aligned}
& {\left[\nabla g\left(x_{k}\right)\right]^{T} d_{k}+g_{i}\left(x_{k}\right)=0 \quad i=1, \ldots, m_{e}} \\
& {\left[\nabla g\left(x_{k}\right)\right]^{T} d_{k}+g_{i}\left(x_{k}\right) \leq 0 \quad i=m_{e}+} \\
& 1, \ldots, m
\end{aligned}
$$

where $d_{k}$ is basis for the search direction.

The Lagrangian function is approximated by an approximate matrix in each iteration and then used to solve the SQP sub-problem.

Hessian matrix $H_{k}$ of Lagrangian function defined by:

$$
\mathrm{L}(\mathrm{x}, \lambda)=\mathrm{f}(\mathrm{x})+\lambda^{\mathrm{T}} \mathrm{g}_{\mathrm{i}}(\mathrm{x}) \text { at } \mathrm{x}=\mathrm{x}_{\mathrm{i}}
$$

where $f(x)$ represents objective function, $g(x)$ constraints, $\mathrm{H}_{\mathrm{k}}$ is approximated by $\mathrm{B}_{\mathrm{k}}$ which is calculated from Quasi-Newton BFGS method,

$$
B_{k+1}=B_{k}+\frac{q_{k} q_{k}^{T}}{q_{k}^{T} s_{k}}-\frac{\left(B_{k} s_{k}\right)\left(B_{k} s_{k}\right)^{T}}{s_{k}^{T} B_{k} s_{k}}
$$

where;

$$
\begin{aligned}
\mathrm{s}_{\mathrm{k}}= & \mathrm{x}_{\mathrm{k}+1}-\mathrm{x}_{\mathrm{k}}, \\
\mathrm{q}_{\mathrm{k}}= & \nabla \mathrm{f}\left(\mathrm{x}_{\mathrm{k}+1}\right)+\sum_{\mathrm{i}=1}^{\mathrm{m}} \lambda_{\mathrm{i}} \nabla \mathrm{g}_{\mathrm{i}}\left(\mathrm{x}_{\mathrm{k}}\right)-\nabla \mathrm{f}\left(\mathrm{x}_{\mathrm{k}}\right) \\
& -\sum_{\mathrm{i}=1}^{\mathrm{m}} \lambda_{\mathrm{i}} \nabla \mathrm{g}_{\mathrm{i}}\left(\mathrm{x}_{\mathrm{k}}\right)
\end{aligned}
$$

Here $\lambda$ is Lagrange multiplier.

Solving SQP as a sub-problem gives $d_{k}$ which is used to generate a new iteration given by equation (19):

$$
\mathrm{x}_{\mathrm{k}+1}=\mathrm{x}_{\mathrm{k}}+\alpha_{\mathrm{k}} \mathrm{d}_{\mathrm{k}}
$$

The final augmented lagrangian function obtained by the combination of Lagrangian and Quadratic penalty method is:

$$
\begin{aligned}
L+f(x)-\sum_{i=1}^{m} \lambda_{i}\left(g_{i}(x)-s_{i}\right) & \\
& +\frac{1}{2} \sum_{i=1}^{m} \rho_{i}\left(g_{i}(x)-s_{i}\right)^{2}
\end{aligned}
$$

where $\rho$ is the penalty parameter and $\mathrm{s}$ are positive slack variable because of non-binding constraints.

\section{SIMULATION RESULTS}

The efficiency of proposed hybrid FPA-SQP technique was tested by implementing it on two standard test systems.

Test System 1: 5-unit non-convex taken from [4] including transmission loses and under constraints like generator limit, valve point effect and ramp rate.

Test System 2: 10-unit non-convex system taken from [36] including transmission losses and under constraints like generator limit, valve point effect and ramp rate.

Proposed technique is coded in MATLAB 13 environment. For each test system 30 distinct runs were performed by setting population size of flowers at 30 and total number of iterations 10000 iterations. The best trial solution for each case is depicted in Figs. 3-6.

\subsection{Test System-1}

FPA-SQP was applied to achieve different solutions of test system 1 taken from [4] by varying weighing factor in the range $0-1$. The variation in weighing factor had significant impact on emission and cost. At a weighing factor value of 0 we achieved best minimized emission but higher cost whereas at weighing factor value of 1 we encountered best minimum cost including significantly reduced emissions as compared to other techniques. At weighing factor value of 0.5 best compromise solution between cost and emissions was achieved. Table 1 shows real power assigned to each generator to 


\section{A Hybrid Flower Pollination Algorithm with Sequential Quadratic Programming Technique for solving Dynamic Combined Economic Emission Dispatch Problem}

achieve best compromise solution whereas Table 2 shows real power assigned to each generator to achieve best cost solution. The cost and emissions from each of these cases are shown in Figs. 3-4 respectively. Tables 3-4 show emission and cost comparison with other techniques available in literature respectively. The average computation time taken by FPA-SQP for solution of 5 unit test system was recorded to be 52.73 seconds.

\begin{tabular}{|c|c|c|c|c|c|c|c|c|c|c|c|c|}
\hline \multicolumn{8}{|c|}{ Table 1: Optimal Dispatch of five-Unit Test System at Best Compromise Solution for 24-Hour Period } \\
\hline \multicolumn{8}{|c|}{ Optimal Dispatch of Five-Unit Test System at Best Compromise Solution for 24-hour Period } \\
\hline Hour & P1 & P2 & P3 & P4 & P5 & Hour & P1 & P2 & P3 & P4 & P5 \\
\hline 1 & 22.658227 & 98.53947 & 112.6737 & 40 & 139.75979 & 13 & 44.553508 & 95 & 173.66165 & 232.82348 & 168.35948 \\
\hline 2 & 37.942274 & 68.53947 & 152.6737 & 90 & 89.759786 & 14 & 74.553508 & 123.71272 & 133.66165 & 250 & 118.35948 \\
\hline 3 & 63.740949 & 38.53947 & 112.6737 & 124.90792 & 139.75979 & 15 & 44.553508 & 93.712719 & 166.51796 & 200 & 158.11927 \\
\hline 4 & 33.740949 & 20 & 152.6737 & 159.81524 & 169.56062 & 16 & 74.553508 & 123.71272 & 130.68568 & 150 & 108.11927 \\
\hline 5 & 55.191343 & 20 & 175 & 194.72312 & 119.56062 & 17 & 52.168635 & 93.712719 & 170.68568 & 100 & 147.87904 \\
\hline 6 & 71.857723 & 20 & 135 & 229.63093 & 159.32037 & 18 & 75 & 87.435715 & 130.68568 & 134.90799 & 187.63878 \\
\hline 7 & 41.857723 & 38.514373 & 175 & 179.63093 & 199.08017 & 19 & 67.317946 & 117.43572 & 170.68568 & 169.81593 & 137.63878 \\
\hline 8 & 71.857723 & 68.514373 & 158.89795 & 214.53897 & 149.08017 & 20 & 75 & 125 & 132.34402 & 204.72386 & 177.39851 \\
\hline 9 & 44.553508 & 98.514373 & 118.89795 & 249.44688 & 188.83995 & 21 & 55.397889 & 95 & 172.34402 & 239.63179 & 127.39851 \\
\hline 10 & 74.553508 & 125 & 158.89795 & 217.1557 & 138.83995 & 22 & 58.46491 & 65 & 132.34402 & 189.63179 & 167.1583 \\
\hline 11 & 44.553508 & 95 & 162.80676 & 250 & 178.59967 & 23 & 68.560262 & 35 & 172.34402 & 139.63179 & 117.1583 \\
\hline 12 & 74.553508 & 125 & 133.66165 & 200 & 218.35948 & 24 & 38.560262 & 49.952286 & 132.34402 & 89.631787 & 156.91808 \\
\hline
\end{tabular}

\begin{tabular}{|c|c|c|c|c|c|c|c|c|c|c|c|}
\hline \multicolumn{12}{|c|}{ Table 2: Optimal Dispatch of Five-Unit Test System at Best Minimum Cost Solution for 24-Hour Period } \\
\hline \multicolumn{12}{|c|}{ Optimal Dispatch of Five-Unit Test System at Best Minimum Cost Solution for 24-hour Period } \\
\hline Hour & $\mathrm{P} 1$ & $\mathrm{P} 2$ & P3 & $\mathrm{P} 4$ & P5 & Hour & $\mathrm{P} 1$ & $\mathrm{P} 2$ & $\mathrm{P} 3$ & $\mathrm{P} 4$ & P5 \\
\hline 1 & 21.333255 & 20 & 112.67348 & 209.81582 & 50 & 13 & 31.940896 & 57.922056 & 165.30619 & 250 & 209.29174 \\
\hline 2 & 51.333255 & 25.19794 & 152.67348 & 159.81582 & 50 & 14 & 37.850329 & 87.922056 & 125.30619 & 200 & 249.05154 \\
\hline 3 & 40.188526 & 20 & 175 & 194.72375 & 50 & 15 & 30.678271 & 117.92206 & 165.30619 & 150 & $\begin{array}{l}199.05154 \\
\end{array}$ \\
\hline 4 & 70.188526 & 50 & 136.34332 & 229.63171 & 50 & 16 & 39.860294 & 87.922056 & 125.30619 & 184.90792 & 149.05154 \\
\hline 5 & 75 & 80 & 175 & 179.63171 & 54.970801 & 17 & 22.560362 & 57.922056 & 165.30619 & 219.81585 & 99.05154 \\
\hline 6 & 66.478151 & 110 & 175 & 214.53967 & 50 & 18 & 13.116849 & 87.922056 & 125.30619 & 250 & 139.75981 \\
\hline 7 & 74.999997 & 124.99995 & 135.29982 & 249.44759 & 50 & 19 & 10.378067 & 57.922056 & 165.30619 & 250 & 179.5196 \\
\hline 8 & 44.999997 & 94.999949 & 175 & 248.18529 & 100 & 20 & 32.135543 & 87.922056 & 175 & 200 & 219.27941 \\
\hline 9 & 74.999997 & 124.99995 & 162.03399 & 198.18529 & 139.75978 & 21 & 32.817086 & 117.92206 & 135 & 234.90793 & 169.27941 \\
\hline 10 & 75 & 101.34653 & 125.30619 & 233.09321 & 179.77243 & 22 & 45.506328 & 87.922056 & 175 & 184.90793 & 119.27941 \\
\hline 11 & 45 & 117.92206 & 165.30619 & 183.09321 & 219.53216 & 23 & 45.820248 & 57.922056 & 135 & 134.90793 & 159.0392 \\
\hline 12 & 61.139496 & 87.922056 & 125.30619 & 218.00112 & 259.29174 & 24 & 70.597755 & 27.922056 & 175 & 84.907928 & 109.0392 \\
\hline
\end{tabular}

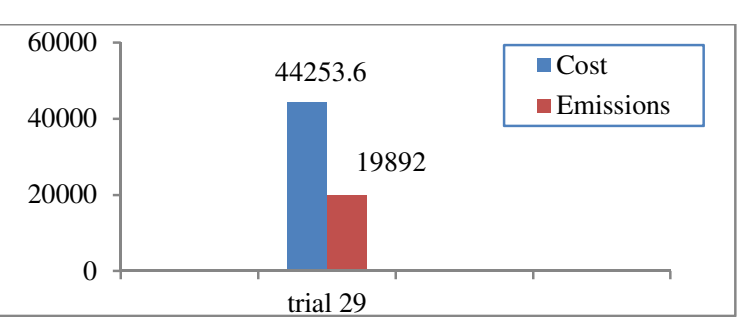

Fig. 3: Best Compromise Solution for Five-Unit Test System

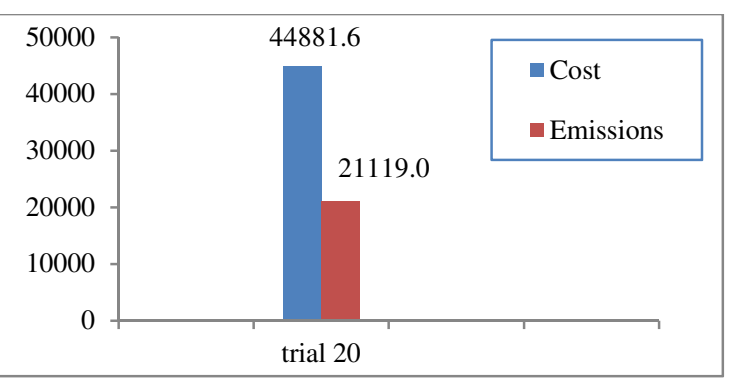

Fig. 4: Best Minimum Cost Solution for Five-Unit Test System

\begin{tabular}{|c|c|c|}
\hline \multicolumn{3}{|c|}{$\begin{array}{l}\text { Table 3: Comparison of Five-Unit Test System } \\
\text { with other Algorithms for Best Minimum Cost } \\
\text { Solution }\end{array}$} \\
\hline \multicolumn{3}{|c|}{ Best Minimum Cost Solution ( $w=1$ ) } \\
\hline Techniques & Cost $(\$)$ & Emissions (Lb) \\
\hline DE-SQP [4] & 43161 & 23080 \\
\hline PSO-SQP [4] & 43263 & 23180 \\
\hline PSO [38] & 47852 & 22405 \\
\hline SA [39] & 48621 & 21,188 \\
\hline EP [39] & 48,628 & 21,154 \\
\hline BA [40] & $44,134.73$ & 22362.22 \\
\hline
\end{tabular}

\begin{tabular}{|c|c|c|}
\hline \multicolumn{3}{|c|}{$\begin{array}{c}\text { Table 4: Comparison of Five-Unit Test System } \\
\text { with other Algorithms for Best Compromise } \\
\text { Solution }\end{array}$} \\
\hline \multicolumn{3}{|c|}{ Best Compromise solution $(\mathrm{w}=0.5)$} \\
\hline Techniques & Cost $(\$)$ & Emissions (Lb) \\
\hline DE-SQP [4] & 44450 & 19616 \\
\hline PSO-SQP [4] & 44542 & 19772 \\
\hline PSO [38] & 50893 & 20163 \\
\hline PS [39] & 47911 & 18927 \\
\hline BA [40] & 45527.8 & 18384.51 \\
\hline FPA-SQP & 44253.6 & 19892 \\
\hline
\end{tabular}




\section{A Hybrid Flower Pollination Algorithm with Sequential Quadratic Programming Technique for solving Dynamic Combined Economic Emission Dispatch Problem}

\subsection{Test System 2}

Similarly test system 2 taken from [36] was solved by proposed FPA-SQP at different values of weighting factor. Solutions produced showed similar variation as observed for 5-unit system when weighing factor was changed. Tables 5-6 show the real power assigned to each of the ten generators to achieve best compromise solution and best cost solution respectively. The average computation time taken by FPA-SQP for solution of 10 unit test system was recorded to be 91.7 seconds.

\begin{tabular}{|c|c|c|c|c|c|c|c|c|c|c|}
\hline \multicolumn{11}{|c|}{ Table 5: Optimal Dispatch of Ten-Unit Test System at Best Compromise Solution for 24-Hour Period } \\
\hline \multicolumn{11}{|c|}{ Optimal Dispatch of Ten-Unit Test System at Best Compromise Solution for 24-hour Period } \\
\hline Hour & P1 & $\mathrm{P} 2$ & P3 & P4 & P5 & P6 & P7 & P8 & P9 & P10 \\
\hline 1 & 150 & 135 & 93.1289 & 120.4065 & 122.8756 & 122.4499 & 129.5854 & 120 & 52.06351 & 10 \\
\hline 2 & 150 & 135 & 73 & 119.6651 & 172.7331 & 137.8997 & 130 & 120 & 54.12057 & 40 \\
\hline 3 & 150 & 135 & 112.681 & 169.6651 & 222.4661 & 153.3496 & 100 & 120 & 80 & 43.42122 \\
\hline 4 & 150 & 135 & 189.285 & 188.5783 & 241.7777 & 160 & 130 & 120 & 80 & 46.84244 \\
\hline 5 & 150 & 135 & 221.4841 & 230.9529 & 241.6445 & 160 & 130 & 120 & 80 & 50.26365 \\
\hline 6 & 150 & 215 & 283.3907 & 241.3682 & 243 & 160 & 130 & 120 & 80 & 53.72492 \\
\hline 7 & 150 & 215.6175 & 315.5903 & 285.9541 & 243 & 160 & 130 & 120 & 80 & 55 \\
\hline 8 & 183.5138 & 222.8839 & 340 & 300 & 243 & 160 & 130 & 120 & 80 & 55 \\
\hline 9 & 263.5138 & 302.8839 & 340 & 300 & 243 & 160 & 130 & 120 & 80 & 55 \\
\hline 10 & 336.7623 & 336.8092 & 340 & 300 & 243 & 160 & 130 & 120 & 80 & 55 \\
\hline 11 & 352.6014 & 413.2514 & 340 & 300 & 243 & 160 & 130 & 120 & 80 & 55 \\
\hline 12 & 393.931 & 420.5173 & 340 & 300 & 243 & 160 & 130 & 120 & 80 & 55 \\
\hline 13 & 331.5867 & 396.835 & 340 & 300 & 243 & 160 & 130 & 120 & 80 & 55 \\
\hline 14 & 251.5867 & 316.835 & 338.1582 & 300 & 243 & 160 & 130 & 120 & 80 & 55 \\
\hline 15 & 171.5867 & 236.835 & 338.0083 & 300 & 243 & 160 & 130 & 120 & 80 & 55 \\
\hline 16 & 150 & 156.835 & 258.0083 & 250 & 237.7843 & 160 & 130 & 120 & 80 & 55 \\
\hline 17 & 150 & 135 & 251.7725 & 200 & 237.6508 & 160 & 130 & 120 & 80 & 55 \\
\hline 18 & 150 & 204.417 & 283.9722 & 250 & 243 & 160 & 130 & 120 & 80 & 55 \\
\hline 19 & 184.1309 & 222.2665 & 340 & 300 & 243 & 160 & 130 & 120 & 80 & 55 \\
\hline 20 & 264.1309 & 302.2665 & 340 & 300 & 243 & 160 & 130 & 120 & 80 & 55 \\
\hline 21 & 257.0184 & 309.5327 & 340 & 300 & 243 & 160 & 130 & 120 & 80 & 55 \\
\hline 22 & 177.0184 & 229.5327 & 260 & 250 & 243 & 160 & 130 & 120 & 80 & 27.20953 \\
\hline 23 & 150 & 149.5327 & 180 & 200 & 214.2708 & 160 & 130 & 120 & 50 & 10 \\
\hline 24 & 150 & 135 & 110.0115 & 150 & 164.2708 & 160 & 100 & 120 & 80 & 40 \\
\hline
\end{tabular}

\begin{tabular}{|c|c|c|c|c|c|c|c|c|c|c|}
\hline \multicolumn{11}{|c|}{ Table 6: Optimal Dispatch of Ten-Unit Test System at Best Minimum Cost Solution for 24-Hour Period } \\
\hline \multicolumn{11}{|c|}{ Optimal Dispatch of Ten-Unit Test System at Best Minimum Cost Solution for 24-hour Period } \\
\hline Hour & $\mathrm{P} 1$ & $\mathrm{P} 2$ & $\mathrm{P} 3$ & $\mathrm{P} 4$ & P5 & P6 & P7 & P8 & $\mathrm{P} 9$ & $\mathrm{P} 10$ \\
\hline 1 & 150 & 135 & 164.8349 & 60 & 73 & 160 & 129.5904 & 120 & 20 & 43.42092 \\
\hline 2 & 150 & 135 & 188.3142 & 60 & 122.8666 & 160 & 99.5904 & 120 & 50 & 46.84207 \\
\hline 3 & 150 & 135 & 235.8437 & 110 & 172.8666 & 160 & 106.1206 & 120 & 80 & 16.84207 \\
\hline 4 & 150 & 135 & 258.0037 & 160 & 222.5995 & 160 & 112.6508 & 120 & 80 & 43.42146 \\
\hline 5 & 150 & 135 & 290.1981 & 210 & 238.307 & 160 & $\begin{array}{l}119.1809 \\
\end{array}$ & 120 & 50 & 46.83999 \\
\hline 6 & 150 & 138.1325 & 340 & 260 & 243 & 160 & 130 & 120 & 80 & 55 \\
\hline 7 & 192.0619 & 135 & 340 & 300 & 243 & 160 & 130 & 120 & 80 & 55 \\
\hline 8 & 191.3961 & 215 & 340 & 300 & 243 & 160 & 130 & 120 & 80 & 55 \\
\hline 9 & 271.3961 & 295 & 340 & 300 & 243 & 160 & 130 & 120 & 79.99999 & 54.99999 \\
\hline 10 & 298.5537 & 375 & 340 & 300 & 243 & 160 & 130 & 120 & 80 & 55 \\
\hline 11 & 371.8022 & 394.0629 & 340 & 300 & 243 & 160 & 130 & 120 & 80 & 55 \\
\hline 12 & 368.4263 & 446.02 & 340 & 300 & 243 & 160 & 130 & 120 & 80 & 55 \\
\hline 13 & 362.4321 & 366.02 & 340 & 300 & 243 & 160 & 130 & 120 & 80 & 55 \\
\hline 14 & 282.4321 & 286.02 & 338.2709 & 300 & 242.8665 & 160 & 130 & 120 & 80 & 55 \\
\hline 15 & 202.4321 & 206.02 & 338.2337 & 300 & 242.7332 & 160 & 130 & 120 & 80 & 55 \\
\hline 16 & 150 & 135 & 335.3035 & 250 & 242.5997 & 160 & 100 & 120 & 50 & 55 \\
\hline 17 & 150 & 135 & 255.3035 & 249.5176 & 242.4663 & 160 & 130 & 120 & 52.05703 & 25 \\
\hline 18 & 150 & 135 & 315.0737 & 299.5176 & 243 & 160 & 130 & 120 & 80 & 43.42119 \\
\hline 19 & 191.3961 & 215 & 340 & 300 & 243 & 160 & 130 & 120 & 80 & 55 \\
\hline 20 & 271.3961 & 295 & 340 & 300 & 243 & 160 & 130 & 120 & 80 & 55 \\
\hline 21 & 264.2811 & 302.2665 & 340 & 300 & 243 & 160 & 130 & 120 & 80 & 55 \\
\hline 22 & 184.2811 & 222.2665 & 262.4979 & 250 & 242.8667 & 160 & 130 & 90 & 80 & 55 \\
\hline 23 & 150 & 142.2665 & 182.4979 & 200 & 192.8667 & 111.4711 & 130 & 120 & 80 & 55 \\
\hline 24 & 150 & 135 & 102.4979 & 150 & 216.8843 & 160 & 100 & 90 & 50 & 55 \\
\hline
\end{tabular}

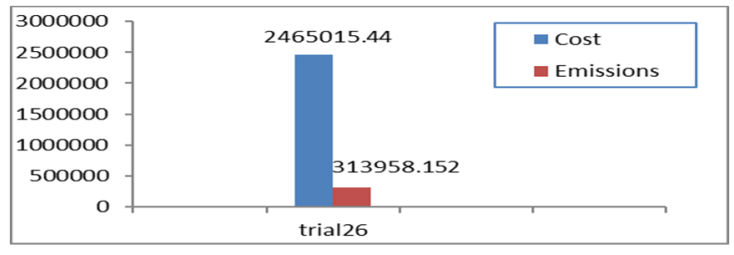

Fig. 5: Best Compromise Solution for Ten-Unit Test System

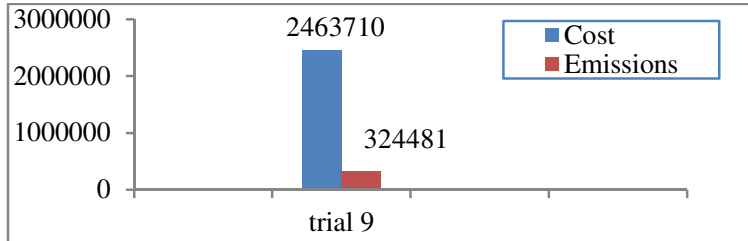

Fig. 6: Best Minimum Cost Solution For Ten-Unit Test System 
Figs. 5-6 show cost and emissions for each of the above-mentioned dispatches respectively whereas Tables 7 and 8 show the comparison of cost and emission with other techniques available in literature for each of the best cost solution and best compromise solution respectively.

\subsection{Discussion}

Results for best cost solution shown in Table 3 for test system 1 shows that, the FPA-SQP was able to acquire an improvement in cost of $3746 \$, 3739 \$$ and $2970 \$$ as compared to EP [39], SA [39], PSO [38] respectively. As for DE-SQP [4], BA [40] and PSO-SQP [4] the proposed technique was able to minimize $1961 \mathrm{Lb}$, 1243.22 Lb and 2061 Lb of emissions respectively. Whereas, for best compromise solution of test system 1 shown in Table 4 the proposed technique was able to achieve an improvement in cost of 196.4\$, 288.4\$, $1274.2 \$, 6639.4 \$$ and $3657.4 \$$ as compared to DESQP [4], PSO-SQP [4], BA [40], PSO [38] and PS [39] respectively whereas the emission levels of each technique were also comparable. The transmission loses incurred in both cases were 193.003 and 190.056 MW respectively.

Similarly, for best cost solution shown for test system 2 shown in Table 7 the proposed technique was able to achieve an improvement in cost in range $10^{6}$ of $0.1217 \$, 0.1085 \$, 0.05599 \$, 0.05309 \$, 0.01799 \$$, $0.00219 \$, 0.00309 \$, 0.010763 \$, 0.018024 \$$ and $0.053091 \$$ as compared to EP [41], PSO [41], AIS [41], I-BFA [33], for DE-SQP [4], PSO-SQP [4], GCABC [42], IBFA [42] and NSGAII [42] respectively at a comparable emission level. Also, for best cost solution of test system 2 shown in Table 8 the proposed technique was able to acquire an improvement in cost in the range of $10^{6}$ and emission in the range of $10^{5}$, of $0.001785 \$$ at $0.01682 \mathrm{Lb}$, $0.005085 \$$ at $0.01112 \mathrm{Lb}, 0.083902 \$$ and $0.049409 \$$ respectively as compared to DE-SQP [4], PSO-SQP [4], DE [43] and MDE [43]. The transmission losses incurred in both cases were 1286.93 and 1286.01 MW respectively.

The comparison with literature proves that effectiveness of FPA-SQP technique. Further to elaborate the transition of FPA-SQP between different phases of search convergence characteristics for 5 unit test system under a fixed hour for 1000 iterations is shown in Fig. 7. From figure it can be seen that FPASQP transitions smoothly among exploration and exploitation phases during its quest for optimal values. The slopes on the characteristic curves indicate exploration whereas the flat regions indicate exploitation.

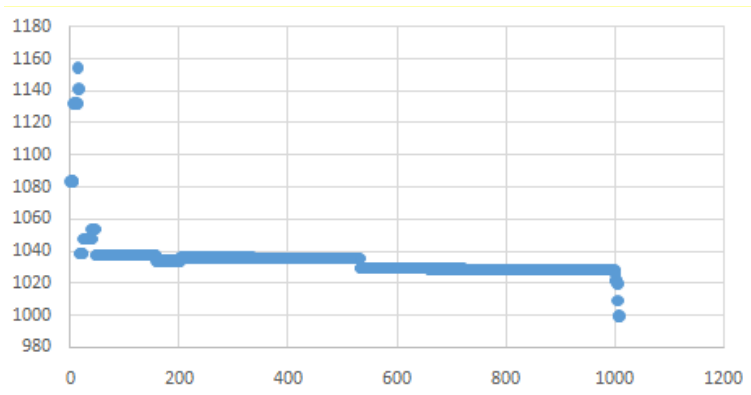

Fig. 7: Convergence Curve for 5 Unit System for a Fixed Hour

\begin{tabular}{|c|c|c|}
\hline \multicolumn{3}{|c|}{$\begin{array}{c}\text { Table 7: Comparison of Ten-Unit Test System } \\
\text { with other algorithms for best minimum cost } \\
\text { solution }\end{array}$} \\
\hline \multicolumn{3}{|c|}{ Best Minimum Cost Solution } \\
\hline Technique & $\operatorname{Cost}^{*} 10^{6}(\$)$ & Emissions $* 10^{5}(\mathrm{Lb})$ \\
\hline EP [41] & 2.5854 & - \\
\hline PSO [41] & 2.5722 & - \\
\hline AIS [41] & 2.5197 & - \\
\hline I-BFA [33] & 2.4817 & 3.2750 \\
\hline DE-SQP [4] & 2.4659 & 3.2405 \\
\hline PSO-SQP [4] & 2.4668 & 3.3023 \\
\hline GCABC [42] & 2.474472 & 2.93416 \\
\hline IBFA [42] & 2.481733 & 2.95833 \\
\hline NSGAII [42] & 2.5168 & 3.174 \\
\hline FPA-SQP & 2.463709 & 3.24481 \\
\hline
\end{tabular}

Table 8: Comparison of Ten-Unit Test System with other Algorithms for Best Compromise Solution

\begin{tabular}{|c|c|c|}
\hline \multicolumn{3}{|c|}{ Best Compromise solution } \\
\hline Technique & Cost*10 $0^{6}(\$)$ & Emissions*10 $10^{5}(\mathrm{Lb})$ \\
\hline DE-SQP [4] & 2.4668 & 3.1564 \\
\hline PSO-SQP [4] & 2.4701 & 3.1507 \\
\hline DE [43] & 2.548917 & 3.084189 \\
\hline MDE [43] & 2.514424 & 2.996616 \\
\hline FPA-SQP & 2.465015 & 3.13958 \\
\hline
\end{tabular}

\section{CONCLUSION}

In this study, a hybrid FPA with SQP was proposed to solve the DCEED problem under the effect of valve point and Ramp rate constraint including transmission losses. The proposed strategy utilizes FPA to initialize 
its search for optimum point and then refines its search by applying SQP. Hybrid FPA-SQP was implemented on IEEE standard 5-unit and 10-unit test system in MATLAB 13 environment. The results obtained indicate that FPA-SQP was able to achieve better solution both in terms of cost as well as emissions. The success of this approach is a motivating factor for future research, exploring more hybrid options and improvement in solution strategies.

\section{ACKNOWLEDGEMENT}

The authors wish to acknowledge the support from Ph.D. and MSc Research Scholars and also the faculty especially Dean and Chairman of Electrical Engineering Department, University of Engineering and Technology Taxila, Pakistan.

\section{REFERENCES}

1. Rehman K., Ahmed A., "A Novel Hybrid Moth Flame Optimization with Sequential Quadratic Programming Algorithm for Solving Economic Load Dispatch Problem", Mehran University Research Journal of Engineering and Technology, Vol. 38, No. 1, pp. 129-142, January 2019.

2. Fayyaz S., Ahmad A., Babar M.I., " Solution of economic dispatch problem using polar bear optimization algorithm", Journal of Fundamental and Applied Sciences, Vol. 11, No. 2, pp. 562577, May 2019.

3. Mandal B. Roy P.K. Mandal S., "Economic load dispatch using krill herd algorithm", International Journal of Electrical Power and Energy Systems, Vol. 57, No. 1, pp. 1-10, May 2014.

4. Elaiw A.M., Xia X., Shehata A.M., "Hybrid DESQP and hybrid PSO-SQP methods for solving dynamic economic emission dispatch problem with valve-point effects", Electric Power Systems Research, Vol. 103, No. 1, pp. 192-200, October 2013.

5. Jeddi B., Vahidinasab V., "A modified harmony search method for environmental/economic load dispatch of real-world power systems", Energy Conversion and Management, Vol. 78, No. 1, pp. 661-675, February 2014.

6. El-Keib A.A., Ma H., Hart, J.L., "Economic dispatch in view of the clean air act of 1990",
IEEE Transactions on Power Systems, Vol. 9, No. 2, pp. 972-978, 1994.

7. Heslin J.S., Benjamin F. H., "A multiobjective production costing model for analyzing emissions dispatching and fuel switching of power stations", IEEE Transactions on Power Systems, Vol. 4, No. 3 , pp. 836-842, 1989.

8. Elaiw M., Xia X. Shehata A.M., "Application of model predictive control to optimal dynamic dispatch of generation with emission limitations", Electric Power Systems Research, Vol. 84, No. 1, pp. 31-44, 2012.

9. Catalao J.P.S., Mariano S.J.P.S., Mendes V.M.F., Ferreira L.A.F.M., "A Practical approach for profit-based unit commitment with emission limitations", International Journal Electrical Power and Energy Systems, Vol. 32, No. 3, pp. 218-224, March 2010.

10. Abido M.A., "Environmental/economic power dispatch using multiobjective evolutionary algorithms", IEEE Transactions on Power Systems, Vol. 18, No. 4, pp. 1529-1537, November 2003.

11. Haroon S.S., Malik T. N., "Short term economic emission power scheduling of hydrothermal energy systems using improved water cycle algorithm", Mehran University Research Journal of Engineering and Technology, Vol. 36, No. 2, pp. 255-272, April 2017.

12. Rezaie H., Kazemi-Rahbar M.H., Vahidi B., Rastegar H., "Solution of combined economic and emission dispatch problem using a novel chaotic improved harmony search algorithm", Journal of Computational Design and Engineering, Vol. 6, No. 3, pp. 447-467, July 2019.

13. Hindi K.S., Ab-Ghani M. R., "Dynamic economic dispatch for large scale power systems: a Lagrangian relaxation approach", International Journal Electrical Power and Energy Systems, Vol. 13, No. 1, pp. 51-56, February 1991.

14. Dillon T. S., Edwin K.W., Kochs H. D., Taud R. J., "Integer Programming Approach to the Problem of Optimal Unit Commitment with Probabilistic Reserve Determination", IEEE Transactions Power Apparatus and Systems, Vol. 97, No. 6, pp. 2154-2166, 1978. 
15. Lowery P. G.,"Generating Unit Commitment by Dynamic Programming", IEEE Transactions Power Apparatus and Systems, Vol. 85, No. 5, pp. 422-426, May 1966.

16. Chen C.L., "Non-convex economic dispatch: A direct search approach", Energy Conversion and Management, Vol. 48, No. 1, pp. 219-225, January 2007.

17. Papageorgiou L.G., Fraga E.S., “A mixed integer quadratic programming formulation for the economic dispatch of generators with prohibited operating zones", Electric Power Systems Research, Vol. 77, No. 10, pp. 1292-1296, August 2007.

18. Xia X., Elaiw A.M., "Dynamic economic dispatch: A review", Online Journal on Electronics and Electrical Engineering, Vol. 2, No. 2, pp. 234-245, 2010.

19. Lu Y., Zhou J., Qin H., Wang Y., Zhang Y., "Chaotic differential evolution methods for dynamic economic dispatch with valve-point effects", Engineering Application of Artificial Intelligence, Vol. 24, No. 2, pp. 378-387, March 2011.

20. Sun J., Palade V., Wu X.J., Fang W., Wang Z., "Solving the Power Economic Dispatch Problem with Generator Constraints by Random Drift Particle Swarm Optimization", IEEE Transaction on Industrial Information, Vol. 10, No. 1, pp. 222-232, February 2014.

21. Chakraborty S., Senjyu T., Yona A., Saber A.Y., Funabashi T.", Solving economic load dispatch problem with valve-point effects using a hybrid quantum mechanics inspired particle swarm optimization", IET Generation, Transmission \& Distribution, Vol. 5, No. 10, pp. 1042-1052, October 2011.

22. Wang Y., Zhou J., Qin H. Lu Y., "Improved chaotic particle swarm optimization algorithm for dynamic economic dispatch problem with valvepoint effects", Energy Conversion and Management, Vol. 51, No. 12, pp. 2893-2900, December 2010.

23. Hemamalini S., Simon S.P., "Dynamic economic dispatch using artificial immune system for units with valve-point effect", International Journal Electrical Power and Energy Systems, Volume
33, No. 4, pp. 868-874, Oxford, England, May 2011.

24. Park J.H., Kim Y.S., Eom I.K., Lee K.Y., "Economic load dispatch for piecewise quadratic cost function using Hopfield neural network", IEEE Transactions on Power Systems, Vol. 8, No. 3, pp. 1030-1038, August 1993.

25. Walters D. C., Sheble G. B., "Genetic algorithm solution of economic dispatch with valve point loading," IEEE Transactions on Power Systems., Volume 8, No. 3, pp. 1325-1332, Piscataway, USA, August 1993.

26. Jayabarathi T., Jayaprakash K., Jeyakumar D.N. Raghunathan T., "Evolutionary programming techniques for different kinds of economic dispatch problems", Electric Power Systems Research, Vol. 73, No. 2, pp. 169-176, February 2005.

27. Khamsawang S., Jiriwibhakorn S., "DSPSOTSA for economic dispatch problem with nonsmooth and non-continuous cost functions", Energy Conversion and Management, Vol. 51, No. 2, pp. 365-375, February 2010.

28. Coelho L.D.S., Mariani V. C., "An efficient cultural self-organizing migrating strategy for economic dispatch optimization with valve-point effect", Energy Conversion and Management, Vol. 51, No. 12, pp. 2580-2587, December 2010.

29. Vo D.N., Schegner P., Ongsakul W., "Cuckoo search algorithm for non-convex economic dispatch", IET Generation, Transmission \& Distribution, Vol. 7, No. 6, pp. 645-654, June 2013.

30. Qaisar J., “A Hybrid Technique for De-Noising Multi-Modality Medical Images by Employing Cuckoo's Search with Curvelet Transform”, Mehran University Research Journal of Engineering and Technology, Vol. 37, No. 1, pp. 29-48, January 2018.

31. Secui D.C., "A new modified artificial bee colony algorithm for the economic dispatch problem", Energy Conversion and Management, Vol. 89, No. 1, pp. 43-62, January 2015.

32. Basu M. "Fuel constrained economic emission dispatch using non dominated sorting genetic algorithm-II", Energy, Vol. 78, No. 1, pp. 649664, December 2014. 
33. Pandit N., Tripathi A., Tapaswi S. Pandit M., “An improved bacterial foraging algorithm for combined static/dynamic environmental economic dispatch", Applied Soft Computing, Vol. 12, No. 11, pp. 3500-3513, November 2012.

34. Basu M., "Hybridization of bee colony optimization and sequential quadratic programming for dynamic economic dispatch", International Journal of Electrical Power and Energy Systems, Vol. 44, No.1, pp. 591-596, 2013.

35. Yang X.S., Karamanoglu M. Xingshi, H., "Multiobjective flower algorithm for optimization", Procedia Computer Science, Vol. 18, No. 1, pp. 861-868, USA, 2013

36. Attaviriyanupap P., Kita H., Tanaka E., Hasegawa J., "A hybrid EP and SQP for dynamic economic dispatch with non-smooth fuel cost function", IEEE Transactions on Power Systems, Vol. 17, No. 2, pp. 411-416, 2002.

37. Basu M., "Dynamic economic emission dispatch using nondominated sorting genetic algorithmII", International Journal of Electrical Power \& Energy Systems, Vol. 30, No. 2, pp. 140-149, 2008.

38. Basu M., "Particle swarm optimization based goal-attainment method for dynamic economic emission dispatch", Electric Power Components and Systems, Vol. 34, No.9, pp. 1015-1025, 2006.

39. Alsumait J.S., Qasem M., Sykulski J.K., AlOthman, A.K., "An improved pattern search based algorithm to solve the dynamic economic dispatch problem with valve-point effect", Energy Conversion and Management, Vol. 51, No.10, pp.2062-2067, 2010.

40. Elaiw A.M., Xia X., Shehata A.M., "Solving dynamic economic emission dispatch problem with valve-point effects using hybrid DESQP", Proceedings of the IEEE Power and Energy Society Conference and Exposition in Africa: Intelligent Grid Integration of Renewable Energy Resources (Power Africa), IEEE, USA, 2012.

41. Basu M., "Artificial immune system for dynamic economic dispatch", International Journal of Electrical Power and Energy Systems, Vol. 33, No.1, pp.131-136, 2011.
42. Marouani I., Boudjemline A., Guesmi T., Abdallah H., "A Modified Artificial Bee Colonyfor the Non-Smooth Dynamic Economic/Environmental Dispatch", Engineering, Technology and Applied Science Research, Vol. 8, No. 5, pp. 3321-3328, 2018.

43. Zuo L., Liu B. Wen Z., Sun H., Di R., Wu P., "Research of Dynamic Economic Emission Dispatch Based on Parallel Molecular Differential Evolution Algorithm". In IOP Conference Series: Earth and Environmental Science, Vol. 170, No. 3, UK, July 2018. 